\title{
JUVENTUDE INTERATIVA: CIDADANIA CONTRA O RACISMO
}

\section{INTERACTING YOUTH: CITIZENSHIP AGAINST RACISM}

Rosangela Malachias

ALACHIAS, R. Juventude Interativa: Cidadania Contra o Racismo. Rev. Bras. Cresc. Desenv. Hum., S. Paulo, 9(2), 1999.

Resumo: A discriminação racial vigente na sociedade influencia a construção das identidades jovem e étnica, afetando ainda as relações de género. Na chamada sociedade global, percebese o aumento dos conflitos sociais, marcados principalmente pela desigualdade das oportunidades. Somente através da percepção das diferenças é que se pode construir a igualdade. $\mathrm{O}$ objetivo do presente artigo é tratar os temas Sexualidade e Drogas, concomitantemente a um terceiro tema, a Cidadania, através da tomada de consciência dos direitos e deveres individuais que afetam a coletividade. O público-alvo foram alunos dos Cursos Pré-Vestibulares direcionados à população de baixa renda, prioritariamente negra, interessada em estudar na USP. Foram selecionanados os alunos de ambos os sexos interessados em participar do Projeto JUVENTUDE INTERA 71 VA. Eles atuaram como agentes multiplicadores de informação junto a outros jovens que terão a chance de vir a conhecer o Projeto. O núcleo temático das aulas, oficinas e produção de textos priorizou a construção positiva das identidades jovem e étnica, calcada no conhecimento da cosmovisão africana sobre a sexualidade, o corpo, a fertilidade, além das noções básicas sobre saúde, beleza, autoestima, prazer, equilíbrio fisico e mental.

Palavras-chave: Juventude negra; Multiplicadores de cidadania; Prevenção; Vulnerabilidade.

A cidadania é mutilada na educação... Quem por acaso passeou ou permaneceu na maior universidade deste país, a USP, não tem nenhuma dúvida de que ela não é uma universidade para negros. E na saúde também a cidadania é igualmente mutilada - já que tratar de saúde num país em que a medicina é elitista e os médicos se comportam como elitistas, supõe freqüentemente o apelo às relações, aquele telefone que distingue os brasileiros entre os que tem e os que não tem a quem pedir um pistolão. (MILTON SANTOS).

Este artigo narra algumas constatações feitas durante a realização do Projeto JUVENTU-
DE INTERATIVA (1997-1999)², direcionado à formação de jovens negros(as) agentes multiplicadores(as) de cidadania e informação, à prevenção ao uso de drogas, à contaminação pela AIDS e demais Doenças Sexualmente Transmissíveis (DST).

A juventude negra vem sendo historicamente visibilizada em espaços permitidos, como a marginalidade das ruas e das instituições de "menores", na servidão dos postos do subemprego e da informalidade, no entretenimento como "artistas" da música ou do esporte - falo este que tem servido como paradigma de ascensão social às demais crianças e jovens pobres da periferia.

1 Jornalista, doutoranda em Comunicação na ECA/USP, professora assistente da FATEC/SP e bolsista do Programa de PopulaçãodaFundação Ma^cArth^ur(^ls9^7^-^ls99) End.: Av. Brasiléa, 91 -02440-060- São Paulo- s^P. E-mail: agyei@usp.br 2 Patrocinio: Programa de População da Fundação MacArthur. Esta pesquisa de intervenção decorre de outra, teórica: MALACHIAS, Rosangela - Ação transcultural: a visibilidade da juventude negra nos bailes black de São Paulo (Brasil) e Havana (Cuba) - Dissertação de Mestrado - PROLAM/USP, outubro/1996. 
Nos Estados Unidos, país que emprega a classificação étnica-racial nos dados populacionais, estudos ${ }^{3}$ sobre saúde comprovam, que as pessoas negras com o mesmo nível salarial das brancas apresentam piores condições de saúde. (BARBOSA: 1998, p.35)

No Brasil, o racismo também afeta objetivamente as condições de vida da população negra e do perfil de morbi-morbidade desse segmento. As explicações sócio-econômicas para as disparidades nos perfis de morbi-mortalidade entre negros e brancos não dimensionam as diferenças de grau e intensidade do que venha a ser pobre e negro, em sociedades históricas estruturadas pelo racismo. (Idem)

Como ignorar um problema que historicamente perpassa as relações sociais, econômicas e culturais deste país?

O JUVENTDE INTERATIVA, nasceu das reflexões sobre as relações sócio-raciais travadas na sociedade brasileira, que afetam objetiva e subjetivamente a saúde física e mental das pessoas. Disparidades sócio-econômicas, discriminação no acesso ao mercado de trabalho, estereotipias nos meios comunicacionais, são alguns dados que demonstram a urgência na proposição de trabalhos que contemplem a questão étnica-racial como viés analítico, assim como se faz com os conceitos classe e gênero.

\section{IDENTIDADE NEGRA, UM "PROBLEMA" METODOLÓGICO}

O olhar pessoal de pesquisadora tem definido nas pesquisas e/ou intervenções desenvolvidas por mim, quem compõe a juventude negra: "jovens de ambos os sexos, inseridos nas categorias de classificação racial - preto e pardo - (adotadas no Brasil pelo IBGE) e que se enquadram no período etário de transição à vida adulta”. (MALACHIAS, 1996) ${ }^{4}$.

Admito um certo receio metodológico dessa postura, porém tento sustentá-la teoricamente a partir do que escrevem $\wedge$ PIZA \& ROSEMBERG (1995, p. 3-4) que entendem por auto-classifica- ção tanto as escolhas de cor feitas pelos indivíduos entrevistados no rol das cores existentes no vocabulário racial brasileiro quanto no vocabulário utilizado pelos censos. Por hetero-classificação entendem a atribuição de cor ou raça realizada pelo conjunto da sociedade brasileira aos descendentes de pretos, pardos, índios e brancos em que um componente racial ou de cor vem associado a posições sociais simbólicas e/ou concretas.

As autoras explicam ainda que, apesar do procedimento do censo ser o de assumir a cor explicitada pelo entrevistado como cor auto-atribuída, as cores escolhidas fora do grupo de cor utilizado pelos censos fazem parte do conjunto de cores surgidas nos processos de integração social entre grupos racialmente diferentes, onde auto e heteroclassificação se mesclam.

Por ser e me auto-classificar negra, durante uma pesquisa por mim realizada em 1994 e $1995^{5}$, automaticamente selecionava com prioridade os jovens fenotipicamente negros, porque esta atitude facilitava o trabalho de coleta numérica significativa dos freqüentadores dos espaços sociais de lazer definidos. Isto seria mais difícil, se utilizasse uma classificação genotípica (que não é visível). Porém, minha opção trouxe-me surpresas particularrnente agradáveis (e outras nem tanto), quando, em algumas ocasiões, durante a aplicação dos questionários, jovens aparente e fenotipicamente identificáveis como 'brancos' (no Brasil) pediam para ser entrevistados. Auto-denominavam-se "pretos", às vezes explicando em seguida serem descendentes diretos de negros (mãe, pai ou avós). Houve também poucos que, inegavelmente pretos, auto definiam-se "pardos"6.

O debate sobre o conceito de "identidade" avança significativamente nas décadas de 80 e 90 como uma nova expressão de resistência ao racismo brasileiro, pela perspectiva das ciências sociais. Todavia, o que também consideramos significativo no período é o aumento de estudos produzidos por e sobre negros. O olhar do pesquisador sobre a sua própria realidade propicia críticas enriquecedoras ao debate metodológico além de ainpliar a discussão do que é ser negro numa sociedade excludente.

3 The Bureau of the Census, in BARBOSA, 1998, p. 35.

4 A Unesco (1980) admite a existência de juventudes, pois ser jovem nos países desenvolvidos é diferente de ser jovem nos países pobres, nos quais a exploração do trabalho infantil é comum. O Projeto JUENTUDE INTERATIVA delimitou inicialmente os multiplicadores na faixa etária de 16 a 20 anos, a fim de envolver os pais no processo formativo. A realidade, entretanto, obrigounos a ampliação dessa faixa etária, pois os negros chegam tardiamente à escola, comparados com os brancos. Isto também reflete no público dos cursos pré-vestibulares.

5 Dissertacão de Mestrado - vide nota 1.

6 Em Cuba, a maioria questionada identificou-se "negra”, embora tenham sido registradas auto-classificações na categoria "mulata". 
Vejamos o que escrevem alguns autores:

ROLAND (1999, p. 18) faz uma pergunta interessante: por que será que no Brasil os brasileiros inventaram mais de cem termos para descrever a característica racial das pessoas? - E responde: - Acho que essa diversidade de palavras, ao invés de ser um indício de que é algo intratável, de que é algo que não pode ser captado por politicas públicas, é, pelo contrário, um indício da importância dessa questão e da necessidade de políticas públicas que realmente possam promover a igualdade racial em nosso pais.

LOPES (1987, p.38-39) conceitua a identidade como "a construção que cada um faz de si mesmo como pessoa".

SOUZA (1983, p.77-78) considera a construção de uma identidade negra "tarefa eminentemente política", que exigiria imprescindivelmente "a contestação do modelo advindo das figuras primeiras" aprendidas com os pais ou substitutos e que ensinam "a ser uma caricatura do branco". A autora exibe sua condição de negra para propor a construção de uma "nova" identidade "gerada a partir da voz de negros (...) fundada, portanto, em seus interesses, transformadora da História - individual, coletiva, social e psicológica".

TEODORO (1987, p.47-48) ao escrever sobre identidade, cultura e educação ressalta:

(...) nós negros, nos reconhecemos primeiro no discurso do branco, e só quando percebemos o modo como tal sistema nos exclui é que dizemos não a ele e iniciamos o conhecimento de nós mesmos, de nosso próprio ponto de vista.

A exclusão começaria com a linguagem expressa pelos sentidos - audição, visão e ainda pela escrita e fala estabelecendo nossa visão de mundo e do existir.

Daí, resulta a exteriorização do pacto semântico, isto é, a maneira pela qual nos identificamos ou não com os valores culturais humanos (...) Dai, uma certa normalidade que consiste na aberração de um indivíduo ter preconceitos negativos contra si mesmo ou contra seu grupo étnico; é que, antes de mais nada ele é um ser humano dentro do mesmo processo cultural do seu opressor. Ele participa do mesmo pacto semântico, até que se instale nele o espírito critico e a necessidade de re-identificação.

SOUZA (1983, p. 77-78) discorda da idéia sobre o negro não aceitar a sua identidade. É que, no Brasil, nascer com a pele preta e/ou outros caracteres do tipo negróide e compartilhar de uma mesma história de desenraizamento, escravidão e discriminação racial, não organiza, por si só, uma identidade negra.

Com este pensamento elabora o conceito sobre o "ser negro", ou seja, a tomada de posse desta consciência para a criação de uma nova, que reassegure o respeito às diferenças. Assim, ser negro não é uma condição dada, a priori, é um vir a ser. Ser negro é tornar-se negro.

Outro autor que discorre sobre a identidade (étnica e cultural) do ‘ser negro’ é BIKO, (1990, p. 65/66), que ao elaborar o conceito de "Consciência Negra” (utilizado na luta contra o apartheid sul-africano, extinto oficialmente no início dos anos 90) une a subjetividade de sua crença espiritual em Deus à objetividade da urgência participativa dos negros na luta para a transformação das estruturas da sociedade.

“(...) numa breve definição, a Consciência Negra procura provar que é mentira considerar o negro uma aberração do 'normal ', que é ser branco. É a manifestação de uma nova percepção de que, ao procurar fugir de si mesmo e imitar o branco, os negros estão insultando a inteligência de quem os criou negros. Portanto, a Consciência Negra toma conhecimento de que o plano de Deus deliberadamente criou o negro, negro. Procura infundir na comunidade negra um novo orgulho de si mesma, de seus esforços, seus sistemas de valores, sua cultura, sua religião $e$ sua maneira de ver a vida".

Aproximando Teodoro, Biko e Santos, diríamos que a participação no pacto semântico ou a 'venda de sua alma ao branco' ocorreria até o momento em que assume a sua 'consciência negra’ ou ainda até 'tornar-se negro'.

\section{SAÚDE E VULNERABILIDADE}

O Projeto JUVENTUDE INTERATIVA tenta também construir um discurso calcado na conscientização e exercício dos direitos e deveres de cidadania para fortalecer nos jovens a vontade de continuar vivendo. A saúde, nessa perspectiva, é um dos componentes da condição cidadã vislumbrada pelos multiplicadores, que na sua maioria são moças e rapazes oriundos da periferia de São Paulo, afro-brasileiros de pele negra e de outros matizes mais claros, que têm em comum a experiência como alunos de cursos pré-vestibulares direcionados à população negra de baixa renda.

Esses jovens têm sonhos, querem ingressar numa universidade pública, estudar e ter urna profissão. Também têm em comum a consciência da origem africana, vendo-a com positividade, ao contrário do que acontece com muitas pessoas negras, que internalizaram o racismo e por isso sentem vergonha do passado de escravidão.

Por exemplo, a juventude negra da periferia de São Paulo mobilizada em torno do Rap (Rhythm and Poetry/Ritmo e Poesia) elabora 
transculturalmente um discurso marcado pela constatação de sua realidade: desemprego, analfabetismo, miséria, e outras facetas do racismo sui generis do país. O estilo musical fortemente inspirado nos rappers norte-americanos mostrase ideal para passar mensagens 'revolucionárias"7.

A concepção de um discurso sobre saúde pública que contemple a cidadania, no atual contexto político econômico neoliberal e globalizante é, sem dúvida, um paradoxo. SANTOS (1996/97) alerta que na saúde também a cidadania é igualmente mutilada - já que tratar de saúde num pais em que a medicina é elitista e os médicos se comportam como elitistas, supõe freqüentemente o apelo às relações, aquele telefone que distingue os brasileiros entre os que têm e os que não têm a quem pedir um pistolão.

O acesso aos equipamentos públicos de saúde obriga ainda aos usuários, a capacidade de decodificar informações nem sempre precisas. A burocracia afasta os que não são alfabetizados ou os empurra para as filas enormes, nem sempre imprescindíveis. Essas dificuldades demonstram que as pessoas capazes de pedir e processar as informações já se diferenciam muito das que mal balbuciam uma palavra, apenas esperam.

Quando a desigualdade é tanta que ter AIDS torna-se apenas um problema a mais dentre os já vivenciados, a mudança de postura no que se refere às práticas preventivas deve ser obrigatória. Repetir decoradamente fórmulas de como se pega ou não se pega AIDS, alertar para a importância do uso do preservativo nas relações sexuais e divulgar os endereços dos postos e centros de referência mais próximos, não altera a exposição aos riscos.

Todavia, quando viver vale a pena, porque é uma experiência nova a cada dia, quando se tem sonhos e objetivos, quando a luta pelo respeito aos nossos direitos se mostra concomitante à assunção das nossas responsabilidades para com a sociedade e para com o nosso corpo, a vulnerabilidade se deteriora e a exposição aos riscos, sempre possível de acontecer, nos remete imediatamente à reflexão e à escolha certa, manter-se com saúde.

O racismo vem sendo combatido pela Declaração Universal dos Direitos Humanos 1948 e também por legislações específicas de diferentes países através de ações individuais e coletivas. Todavia, sobrevive nas práticas legitimadas (e nem sempre conscientes) dos indivíduos e das estrutu- ras de poder que, contraditoriamente, adotam o discurso da igualdade.

Para o geógrafo Milton Santos, o Brasil, ao longo de sua história, vem assumindo uma subordinação à economia, calcada no regime escravista de expropriação. Valoriza-se os que têm em detrimento dos que são. Vale mais ter do que ser e quem tem é uma minoria, que acossa privilégios confundindo-os com direitos.

Embora o Brasil não assuma o racismo como prática legitimada no país, dados oficiais sobre a condição de vida da população indicam a vulnerabilidade dos negros, tal qual ocorre nos países onde o racismo sempre foi assumido, reconhecido e legislado ${ }^{8}$ pelo governo como os Estados Unidos e a África do Sul. (BARBOSA, 1998).

\section{JUVENTUDE URBANA}

Nos centros urbanos, os jovens ocupam espaços geográficos definidos não somente por questões sócio-econômicas, mas principalmente por identidades culturais. São as gangues, galeras e grupos de orientação diversificada: musical, esportiva (torcidas de futebol), violenta, racista, étnica, religiosa etc. (SPÓSITO, 1994). A rua torna-se palco de novas manifestações de socialização, sociabilidade e violência. Cresce o número de moradores de rua, muitos deles, meninos e meninas.

Estar na cidade, fazer parte dela, representaria a idéia de cidadão, se a noção de cidadania também não implicasse o acesso aos direitos e deveres individuais e coletivos. Como conceber igualdade numa sociedade fundamentada na escravidão, e que ao longo de sua história concentrará suas riquezas nas mãos de uma elite minoritária, branca, em detrimento de uma massa jogada na miserabilidade?

Talvez uma das possibilidades seja a constatação da desigualdade seguida de propostas alternativas que insiram os excluídos. Inserir significa também dar voz àqueles que não falam; expor o que está implícito, tocar na ferida, sentir sua dor e cauterizá-la. Perceber a cicatriz, não escondê-la, mas orgulhar-se dela, como um sinal que assume o passado, vivencia o presente e acredita nas perspectivas do futuro.

Por essa razão, os estudos que contemplam a questão étnica e racial são um indicativo à bus-

8 Racismo é crime inafiançável no Brasil, todavia, prová-lo e puní-lo na justiça constitui-se um esforço imenso dos denunciantes que encontram pela frente uma estrutura de poder que tenta, de todas as formas, desconfigurar o crime, transformando-o, por exemplo, em injúria, fiançável. Em 1994, o regime do Apartheid que legislava o racismo na África do Sul em detrimento da população negra foi abolido, o que não significa o seu fim. Nos EUA, a tradição de igualdade de direitos sobrevive, em alguns estados, com a prática da segregação. “Segregados, mas iguais”. 
ca de soluções às desigualdades; e quando são produzidos sobre e por negros tornam-se ainda um exercício metodológico, porque impõem aos seus propositores, uma vigilância constante do uso do discurso científico e não militante; não dogmático, porém, abertamente compromissado (FALS BORDA, 1988) com a transformação da história.

\section{INTERVENÇÃO}

Alunos e ex-alunos de cursos pré-vestibulares direcionados à população de baixa renda, preferencialmente negra, participaram (e participam) do Projeto JUVENTUDE INTF,RATIVA. Essa juventude reside em diferentes e afastados bairros da cidade, sonha com a possibilidade de ingressar na USP ou em qualquer outra universidade de alto nível. É este sonho que diferencia esses rapazes e moças daqueles que apenas almejam o ‘espaço permitido', limitado pela crença de que as pessoas têm os seus lugares, "o lugar de negro'`. Lugar esteriotipado pela marginalidade ou exaltado pelo lúdico, o entretenimento inusical, futebolístico, e praticamente inacessível à grande maioria dos jovens pobres.

Em comum, têm a história ancestral de apresamento, resistência, expropriação. Graças à obrigatoriedade da disciplina Cidadania ${ }^{9}$, e também à identidade étnica fortalecida no espaço da sala de aula, onde pela primeira vez são maioria, vêem-se como cidadãos com direitos e deveres. Querem fazer parte da sociedade que os exclui e para isso lutam pela aquisição do que deveria ser básico: a educação.

São estes jovens que compõem o JUVFNTUDE INTERATIVA, porque eles são multiplicadores natos. Em geral conquistam o respeito da família, porque atingiram o maior nível de escolaridade do grupo (embora ela ocorra tardiamente comparada ao alunado branco, que conclui o ensino básico e o médio antes do negro). Estes jovens são respeitados no bairro. Há relatos de alunos que frente a uma abordagem de um possível assaltante foi protegido por outros jovens, que os identificaram. "Os caras da rua sabem que estamos vindo do cursinho e não deixam ninguém mexer com a gente" - explica um aluno residente na periferia.

Por terem um sonho - que necessariamente não é estimulado por drogas lícitas ou ilícitas eles já se diferenciam de um contingente juvenil excluído desse novo milênio. Muitos têm em seu breve currículo etário de 18 a 24 anos de vida em média - experiências concretas e violentas de discriminação racial: na procura de emprego, na volta para casa depois de uma festa interrompida pela abordagem policial, nas brigas ocorridas na escola com colegas e até no relacionamento com professores que expressaram seu preconceito.

Logicamente nem todos conseguem passar na Fuvest, todavia o processo que vivenciaram, estudo, debates, auxilia a construção de uma identidade cidadã, que não restringe mais a mobilização dessa juventude na cidade. A mobilização referida nao é somente a geográfica, mas sim a que os faz 'conquistar a cidade, o urbano', apropriando-se dos espaços culturais antes ignorados; alterando a sua relação com os equipamentos públicos, que passam a ser reivindicados para eventos por eles organizados. A USP deixa de ser um lugar inatingível e se torna um local para a população adquirir conhecimento, inforrnação, além de usufruir de seus serviços oferecidos à comunidade. Os Postos de Saúde, os Centros de Referência, passam a ser freüentados para a solicitação do preservativo, para a orientação sexual e demais serviços.

Os jovens que chegaram no curso pré-vestibular olhando para o chão, tomam consciência do seu lugar no mundo e tal como definiu Biko, erguem a cabeça em desafio aos discriminadores. Tornam-se referência àqueles que vivem em condições tão ruins, que nem se importam com a contaminação da AIDS e outras $\wedge$ DSTs.

Nas dinâmicas desenvolvidas no projeto JUVENTUDE INTERA TI VA falamos de história, arte, saúde, sexualidade, gênero, racismo, cidadania, trabalho, drogas, família e outros ternas, objetivando o nosso fortalecimento enquanto indivíduos que buscam laços de solidariedade nas relações sociais travadas no coletivo.

\section{TREINAMENTO DOS A GENTES MUL TIPLICADORES}

\section{Relato - Cidadania Contra o Racismo}

Dois outros Projetos, denominados respectivamente Anexo I do JUVENTUDE INTERA TI VÁ e Anexo II, foram elaborados por mim, após os encontros de Consultoria com a Educadora de Saúde Pública Ana Maria Souza, do CRT AIDS - do bairro Saúde e assistente social do Hospital do Servidor Público do

9 A maioria dos cursos pré-vestibulares para a população de baixa renda adota a disciplina Cidadania, que em geral é obrigatória. Nela são discutidos diferentes assuntos que propiciam o debate e a consciência dos problemas sociais do país. 
Estado de São Paulo. A escolha de Ana tem a ver com a sua história. Filha de mãe branca e pai negro, sempre se identificou como negra, apesar de sua pele clara. A identidade étnica frisada por ela resultou de seus estudos sobre o Movimento Negro na sua pós-graduação na PUC/SP, nos anos 80. As dificuldades iniciais para a ascensão no mercado de trabalho também a fizeram perceber que a cor da pele de uma pessoa pode, no Brasil, determinar as suas chances.

Há mais de 12 anos trabalhando com educação e saúde pública, Ana Maria, ao ler o Projeto original do JUVENTUDE INTERATIVA, compreendeu que, além do trabalho específico da prevenção teríamos o desafio de tentar intervenções direcionadas à cidadania e a etnicidade. Apesar de sua experiência também como membro de uma entidade do movimento negro ${ }^{10}$, afirmou não saber como proceder e me sugeriu um desdobramento, ou seja, a releitura do Projeto original priorizando os objetivos. Discutimos os passos a serem tomados com o cuidado de escolher os verbos que realmente indicassem as ações esperadas. O mesmo foi feito na redação do Projeto para a Produção do Material Informativo.

Na verdade, Ana ministrou-ine dois exercícios redacionais, e eu mudei meu papel de professora de Redação para aluna. Foi difícil reduzir as idéias iniciais a passos concretos, factíveis de serem realizados. Ambos projetos têm praticamente a mesma justificativa, diferem nos objetivos geral e específicos.

O treinamento aconteceu nos meses de abril e maio de 1999, embora as turmas ${ }^{11}$ de 1997 e 1998 tenham participado de dinâmicas regulares que aliavam a prática redacional com exercícios de observação e abstração. Os relatórios dos grupos e os textos individuais priorizavain temas como cidadania, amor, sexo, prevenção, drogas, violência, inídia...

Nem todos os alunos que deram seu nome puderam participar do treinamento e as razões eram mais do que justificáveis. Duas alunas comprometidas com as oficinas (Kamila e Débora) ingressaram na UNESP - Universidade Estadual Paulista, no interior de São Paulo, respectivamente nas cidades de Franca e Presidente Prudente e tiveram que se mudar para lá. Confesso que ao "perdê-las" senti um pouco de tristeza, porém ao ver duas novas alunas negras ingressando na universidade pública, a alegria foi muito maior.

Alunos ${ }^{12}$ multiplicadores - primeira turma:

1. Flaviane Aparecida da Silva, 21 anos;

2. Jone Geraldo Ferreira, 30 anos;

3. Kátia Regina da Silva, 22 anos;

4. Leandro Santos, 22 anos;

5. Marcos Silva Freitas, 21 anos;

6. Rachel Quintiliano, 21 anos;

7. Robson Leite Brasil, 23 anos;

8. Rosangela de Oliveira Santos, 21 anos.

O uso da primeira pessoa faz-se necessário neste breve relato.

Coube a mim, coordenar as atividades mais específicas sobre cidadania e etnicidade e este desafio foi explicitado aos alunos. Eles sabem quais são os objetivos do JUENTUDE INTERATIVA e como negros, vivenciam o racismo, podem percebê-lo, assim como reconhecem a dificuldade que muitos negros têm na sua afirmação identitária. Estas coisas são freqüentemente debatidas por eles.

Soluções? Quem as têm? Resolvemos procurá-las, com a consciência de que podemos estar repetindo fórmulas já usadas, todavia, o reconhecimento e a visibilidade de nossa preocupação, já a diferencia das abordagens que sequer admitem a possibilidade da diferença étnica-racial ser um fator de vulnerabilidade relevante, que deve ser considerado nos trabalhos de prevenção.

Assim, Leandro, Jone, Rachel, Flaviane, Marcos, Kátia, Rosangela Oliveira, Marcelo e eu, seguimos para o Parque da Luz. Na entrada, propus ao grupo (éramos nove pessoas, um dos alunos trabalhava naquela manhã e não pôde ir) que nos dividíssemos em três grupos e entrássemos no parque para um passeio silencioso. Deveríamos observar tudo, em especial, os rostos das pessoas que ali estavam e imaginar uma história para cada uma delas. Este passeio duraria

10 O NAÇÃO CERCAB (NC) é uma entidade sem fins lucrativos, fundada em 1989 por um grupo de estudantes negros preocupados com a questão educacional e cultural. O NC promoveu diversos seminários e um Congresso Estadual, na Faculdade de Direito da USP.

11 Refiro-me aos alunos do curso Pré-vestibular NCN - Núcleo de Consciência Negra, localizado no campus da USP, que sediou o Projeto JUVENTUDE INTERATIVA durante um ano - 1997 a 1998. Em agasto de 98, o Projeto sai do NCN e passa objetivar alunos dos diferentes cursos similares.

12 Estes alunos também fizeram as dinâmicas com colegas de classe, (média de 80 a 90 alunos/aula) todavia assumiram o compromisso de participar do treinamento fechado, restrito àqueles que optaram ser multiplicadores de cidadania. 
15 minutos e marcamos um ponto de encontro, no alto de um monte, no centro do parque.

Quinze minutos depois estávamos lá, os nove, e fizemos um círculo para trocar nossas impressões. Antes, porém, fizemos uma dinâmica de apresentação, trocando os pares e conversando sobre nossa vida e nossos sonhos. Apesar de já nos conhecermos, um apresentou o outro e todos se impressionaram com o "sonho" de Leandro, (que foi lembrado depois, em outras ocasiões) - “Ter uma vida digna”.

Rachel, que apresentou Leandro explicou: "para ele, ter uma vida digna significa ter onde morar, onde dormir, o que comer, estudar, ter trabalho, e condições de viver com dignidade, coisas que estas pessoas aqui não têm”.

Apesar do abandono, o Parque da Luz mostrava ainda sinais de um passado glorioso, com coretos, estátuas e fontes. Dentre os visitantes, observamos que algumas mulheres eram "prostitutas pobres" e que usavam o parque para seus programas. Leandro disse que eram pessoas “que ninguém quer”, isto porque eram na maioria "moradores de rua, velhos e prostitutas". Marcelo percebeu que as pessoas olhavam para ele e seus dois colegas com surpresa, talvez porque comparados aos demais "estavam bem vestidos”. Marcos notou alguns homens lavando roupa no lago. "Eles devem morar aqui". Rosangela Oliveira supôs que fossem imigrantes nordestinos e eu senti a falta de crianças, que em geral lotam os parques nos finais de semana.

Sugeri depois que saíssemos em direção a outro lugar ali perto. Fomos à Pinacoteca, conhecida apenas por mim e por Rachel. Para os demais, era a primeira visita a um museu. Marcelo Dias, desenhista, quase "pirou” quando entrou no prédio e começou a ver todas as telas do acervo, perguntou-me se um dia poderia ver seus desenhos num museu e eu disse que isto dependeria dele e da sua dedicação à arte. $\mathrm{O}$ grupo se espalhou pelo prédio imenso e foi engraçado ver os meninos brincando de "esconde-esconde” com os seguranças. "É que eles não saem do nosso pé”, disse Marcos.

Rachel chamou a todos para a sacada e disse: "olhem o Parque da Luz, daqui ele fica mais bonito, nem parece que está abandonado”. Jone não deixou por menos, comparou os rostos das pessoas que estavam no museu (muito cheio, àquela hora da manhã, 11h, mais ou menos) com as que estavam no Parque, lembrando que não caminhamos mais de 200 metros.

Kátia disse que sempre pegou o trem e nunca havia entrado no Parque, nem na Pinacoteca. Como é possível estar numa cidade e não olhar para ela?

\section{CONSIDERA ÇÕES FINAIS REFLETINDO SOBRE O FUTURO}

Meses depois retornamos ao parque da Luz, o JUVENTUDE INTERATIVA na sua fase final - ou melhor - inicial. O fim do patrocínio MacArthur representa a vida própria que o Projeto ganha, caminhando com os pés dos jovens negros partícipes.

Voltar àquele parque deu ânimo aos alunos. O abandono foi substituído por um trabalho restaurador, que deu vida nova ao lugar. Há agora, muitas flores nos jardins antes abandonados. Turistas argentinos e japoneses tiram fotografias substituindo os mendigos e moradores de rua que antes ocupavam o espaço. O portão de acesso à Pinacoteca do Estado - imaginem - estava aberto e o público, circulava livremente de um lugar para o outro.

“As pessoas que ninguém quer” já não fazem parte do novo Jardim da Luz. Ficamos felizes com tanta beleza, valorizada ainda mais com as esculturas de artistas internacionais famosos, espalhadas pelo parque, dando brilho e estranheza às alamedas antes desertas.

Associamos o novo parque ao nosso novo momento. Afinal, o JUVENTUDE INTERATIVA também se modifica. Seria um sinal de bom augúrio? Sim, se pensarmos positivamente e contabilizarmos os resultados:

1.) o projeto ganhou sede própria;

2.) os jovens saem pela cidade e interior do estado ministrando oficinas;

3.) parcerias são estabelecidas propiciando novos caminhos de atuação: Instituto do Negro Padre Batista, Fala Preta Organização de Mulheres Negras, Estação Ciencia/USP; Grupo Luz e Esperança da Federação Espírita do Estado de São Paulo (FEESP), Fundação Cultural Palmares.

“As pessoas que ninguém quer” não deixaram de existir. Cientes de seu direito à vida, tomando nas mãos o seu destino, terão condições de superar a vulnerabilidade que as cerca, de reivindicar e lutar por uma vida digna, com saúde, moradia, escola, trabalho, lazer...

\section{JUVENTUDE ESCRAVIZADAA DEGRADAÇÃO DA SAÚDE}

A saúde física e mental da população negra foi histórica e dialeticamente afetada pela sua condição de vida. Com o passar dos séculos, a violência da escravidão deu lugar às práticas racistas e discrirninatórias. 
Embora haja bibliografia abundante sobre escravidão no Brasil, nem sempre quando se fala do assunto menciona-se a idade dos homens e mulheres inseridos nesta condição. MORENO FRAGINALS (1977, p. 16-19) ao contrário, faz um inventário preciso do sistema escravista analisando diversos aspectos levados em consideração pelo tráfico negreiro para a normalização do trabalho nas plantações cubanas, nas demais colônias caribenhas e latinoamericanas. O autor inclui a faixa etária dos homens e mulheres traficados para nosso continente evidenciando a lógica econômica da expropriação.

A juventude era um fator fundamental para o tráfico negreiro, pois representava longividade para o trabalho e conseqüentemente lucro para os compradores. Entenda-se longividade como um período muito curto, pois o excesso de trabalho, em média de 18 horas diárias (Idem, p. 18), e os maus tratos que se iniciavam no apresamento e embarque nos navios negreiros - causavam elevados índices de mortalidade dos escravizados.

Até princípios do século XIX, os jovens de 15 a 20 anos de idade eram os mais cobiçados pelos negociantes e a partir de 1830, inicia-se o tráfico maciço de crianças com idade entre 9 a 12 anos. As idades eram fixadas aproximadamente pela aparência dos jovens, logo, uma técnica passível de erro. Todavia, Moreno Fraginals comenta a experiência dos traficantes como redutora dessa margem principalmente porque faziam descrições detalhadas da aparência física dos africanos e africanas levados ao mercado.

$\mathrm{O}$ fato do continente Africano reunir uma multiplicidade de grupos étnicos com idiomas, religiões, e demais manifestações culturais diversificadas foi utilizado como "ferramenta" ao processo expropriatório. Estos africanos provenian de culturas cimentadas en la tradición oral donde el saber, es decir, la formación integral, era privilegio de los mas viejos y, especificamente, de los ancianos. (MORENO FRAGINALS, 1997, p. 18).

A lógica do sistema favoreceu a interrupção do processo de socialização dos jovens africanos pertencentes a diferentes grupos étnicos, pois ao priorizar o tráfico exclusivo dos mais jovens, importava-se para as colônias os "me- nos cultos" no sentido da "acumulação do saber" e da tradição africana, transmitida oralmente aos mais jovens pelos anciães dos grupos. Facilitava-se a imposição de novos padrões culturais aos adolescentes, que acabavam vivendo mais tempo fora da África, distantes de uma socialização tradicional ao seu grupo de origem e, portanto, mais propícios à adaptação que a sublevação.

A diversidade étnica favorecia portanto muito mais o conflito entre os escravizados que a sua união. Obstaculizava-se assim, a formação de uma consciência de classe frente a exploração comum, fomentando em seu lugar a constituição de grupos excludentes ${ }^{13}$. À diferença interétnica somariam-se outras formas de distinção entre negros africanos e crioulos ${ }^{14}$; entre negros e mulatos, mamelucos, caboclos e outras designações dadas aos frutos da miscigenação.

Ao refletirmos sobre esses fatos constatamos que para aquela massa negra, a princípio, a cor da epiderme não era o fato mais importante, que a pudesse unir e organizar. A solidariedade e a resistência nasciam muito mais da identidade étnica-cultural (língua, religião, crenças) e logicamente da própria condição de aprisionamento.

Do ponto de vista dos colonizadores, a cor também era um detalhe, pois a literatura indica que os escravizados eram comumente identificados pela sua etnia (Mina, Angola, Bantu...) comprovando que os negros não foram escravizados porque eram negros, (MUNANGA, 1986) e sim porque nascia um sistema de dominação e enriquecimento calcado na exploração de outros povos. Todavia, a hierarquização imposta na divisão social do trabalho relegará aos portadores de tons epidérmicos escuros, os postos mais baixos no mercado de trabalho que começava a se configurar.

Durante 3,5 séculos, apresamento, tortura, trabalho compulsório, perda da identidade, violência foram os instrumentos utilizados para a perpetuação do sistema. Em contrapartida, os negros e descendentes expressaram a sua resistência cotidiana nas manifestações transculturais.

A abolição tardia ${ }^{15}$ da escravidão no Brasil obriga o enfrentamento de uma nova realidade: como incorporar a imensa população negra à sociedade nacional?

13. Tradução livre do espanhol. Ver original MORENO FRAGINALS, 1977 p. 18.

14 Embora no Brasil, popularmente, a palavra crioulo possa designar pessoas da raça negra, neste caso, ela se refere à conreta signifcação, ou seja, às pessoas nascidas na América Latina.

15 Tardia também em Cuba, ano 1886, em relacão aos demais países latino-americanos e caribenhos, a saber: “(...) Haiti (1790); Santo Domingo español (1801); México (1829); Colômbia (1851); Uruguay (1853); ^Venezuela (1854); Perú (1855); ^Argentina (1864); Cuba (1886) y, por último, en Brasil (1888). En las colônias inglesas del Caribe la esclavitud dejó de existir en 1833; en las francesas, en 1848; y en EEUU, en 1863” (apud SERVIAT, 1986, p. 56/57). 
O tempo evidencia que esta questão ainda não seria totalmente respondida, pois a mobilização negra, em especial nas grandes cidades como São Paulo, Rio de Janeiro e Salvador retrata, no início do século XX, a luta pela "integração" social efetivada na denúncia do preconceito e do racismo.

Nos anos 60 e 70, os movimentos negros recusam o mito da democracia racial brasileira e na década de 80, a universidade evidencia científica e oficialmente os índices de exclusão registrados no acesso ao sistema educacional e ao mercado de trabalho (IBGE). Nos anos 90 aumenta a visibilidade de uma classe média negra com poder de consumo reivindicando o empoderamento (enpowerment) da população negra, com políticas de ação afirmativa.
O discurso de saúde perpassa esses momentos da história ganhando sonoridade nas reivindicações dos movimentos sociais, em especial no das mulheres, que na luta feminista passam a construir o conceito de gênero.

Dentro dessa luta, a diversidade étnica também é exaltada, primeiro nos EUA, pelas woman of colour e posteriormente no Brasil, pelo movimento de mulheres negras.

A luta das mulheres explícita a necessidade do debate dos direitos individuais e coletivos à saúde reprodutiva, à sexualidade e se torna referencial para os trabalhos futuros no campo da prevenção com outros grupos sociais.

\begin{abstract}
The existence of racial discrimination in society influences lhe construction of young and ethnic identities, and it also affects lhe social relations between men and women. Social conflicts and inequality of opportunities are growing in lhe global society. Only through tbe perception of differences can we build equality. (OBJECTIVES) The present article aims to deal with the themes of Sexuality and Drugs simultaneously with a third one: Citizenship, because it is necessary to develop the individual conscience about rights and duties to obtain the collective transformation. (TARGET) The subjects were students attending courses directed to the poor population, specially black people, interested in studying at the University of São Paulo. (METHODICAL WORK) The Project selected boys and girls who were interested in participating in the INTERA CTI VE YOUTH Project. They acted as information multiplier agents amongst other youths who will have the chance to get to know the Project later on. The classes, workshops and text-productions emphasised the positive construction of young and ethnic identities, based on the knowledge of the African cosmic view about sexuality, the body, fertility, and also basic notions about health, beauty, self-esteem, pleasure, mental and physical balance.
\end{abstract}

Key-words: Black Youth; Citizenship multipliers; Prevention; Vulnerability.

\section{REFERÊNCIAS BIBLIOGRÁFICAS}

AYRES, J.R.d.C.M. Educação preventiva e vulnerabilidade às DST/AIDS e abuso de drogas entre escolares. como avaliar a intervenção. São Paulo, FDE, 1996. [Caderno Idéias, 29: Papel da educação na ação preventiva ao abuso das DSTiAIDS].

BARBOSA, M.l. Racismo na saúde. São Paulo, 1998. [Tese de Doutorado - Faculdade de Saúde Pública da USP].

BIKO, S. Escrevo o que eu quero. São Paulo, Atica, 1990. (trad. Grupo Solidário São Domingos) (apres. da edição brasileira: Benedita da Silva).

CONE, J. Malcolm X et Martin Luther King. Les efJèts d'une collère noire. Genève, Labor et Fides,1991.

FALS BORDA, O. Aspectos teóricos da pesquisa participante: considerações sobre o significado e o papel da ciência na participação popular. In: BRANDAO, C.P. Pesquisa participante. São Paulo, Brasiliense, 1988.
LOPES, H. T. Educação e identidade. Cadernos de Pesquisa Fundação Carlos Chagas, 63 nov. 1987. (N. temático: Raça Negra e Educação, Fund. Carlos Chagas, São Paulo).

MADEIRA, F. R. Por que o jovem na Grande São Paulo? São Paulo, Fundação Seade - Sistema Estadual de Análise de Dados, 1988. (Coleção Realidade Paulista: O jovem na Grande São Paulo).

MALACHIAS, R. Um olhar social e racial da sociedade. Imã, 3, maio junho 1994. (Jornal dos Alunos do Prolam - Programa de Pós-Graduação em integração na América Latina da Universidade de São Paulo).

MALACHIAS, R. Ação transcultural: a visibilidade da juventude negra nos bailes black de São Paulo (Brasil) e Havana (Cuba). São Paulo, 1996. [Dissertação de Mestrado - Programa de Pós-Graduação em Integração da América Latina da Universidade de São Paulo].

MORENO FRAGINALS, M. Aportes culturales y. In: África en América Latina, México, UN ESCO-SIGLO XXI, p.13-33, 1977. 
MUNANGA, K. Negritude - usos e sentidos. São Paulo, Ed. Ática, 1986.

PIZA, E. \& ROSEMBERG, E. Cor nos censos brasileiros. São Paulo, NEEGRI, no prelo. (Núcleo de Estudos sobre Educação, Gênero, Raça e Idade do Programa de Estudos PósGraduados da PUC/ SP - Pontiíícia Universidade Católica de São Pau1^O,1995).

RAP... ensando a educação. Caderno da Secretaria Municipal da Educação, São Paulo, PMSP, 1992.

ROLAND, E. Gênero e raça e a promoção da igualdade. Brasília, Programa Nacional de Direitos Humanos, 1999.

SANTOS, M. O preconceito. São Paulo, Imprensa Oficial do Estado, 1996/1997.

SERVIAT, P. El problema negro en Cuba y su solución definitiva. La Habana, Ed. Política, 1986.
SILVA, C. B. P. Da Terra das Primaveras à Ilha do Amor: reggae, lazer e identidade cultural. São Luís do Maranhão, Edufma, 1995.

SOUZA, N. S. d. Tornar-se negro ou as vicissitudes da identidade do negro em ascensão social. Rio de Janeiro, Ed. Graal, 1983.

SPÓSITO, M. P. A sociabilidade juvenil e a rua: novos conflitos e ação coletiva na cidade. Tempo Social, 5(1,2): 161 -178,1993. (editado em 1994) (Revista de Sociologia da USP, São Paulo).

TEODORO, M. d. L. Identidade, cultura e educação. Cadernos de Pesquisa da Fundação Carlos Chagas, 63, nov. 1987. (N. Especial: Raça Negra e Educação, São Paulo, Fund. Carlos Chagas).

UNESCO. La jeunesse dans les annés 80. Paris, Les Presses de l’Unesco, 1981.

ZALUAR, A. A máquina e a revolta. São Paulo, Brasiliense, 1985. 